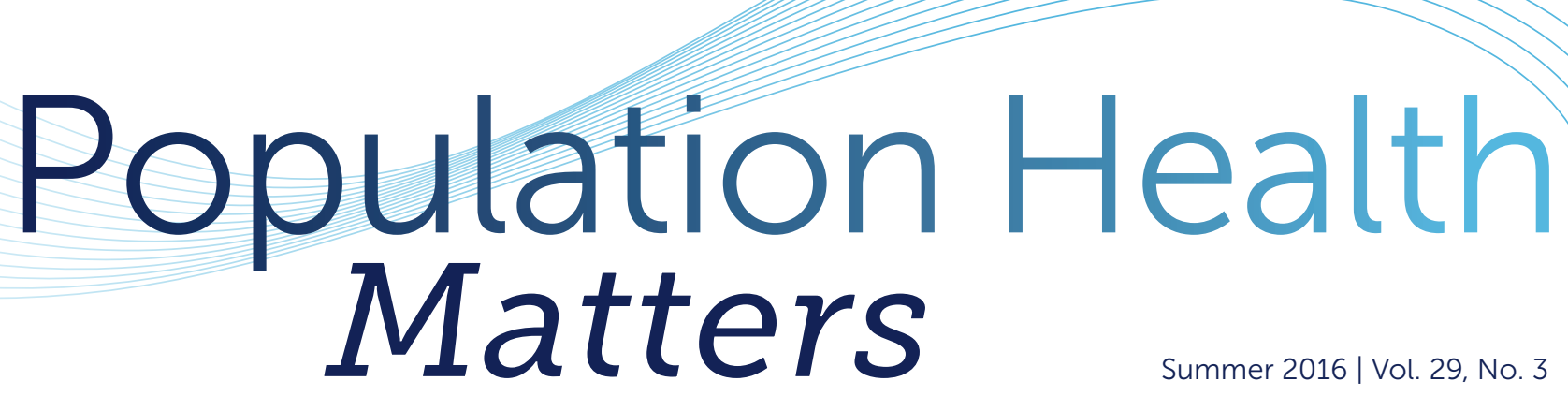

\title{
Present At the Creation
}

\begin{abstract}
Caroline Golab, PhD is Jefferson College of Population Health's Associate Dean for Academic and Student Affairs. In 2007, she was the consultant who conducted a feasibility study and developed the business plan for the new school. After the TJU Board of Trustees approved the proposal in 2008, she was asked to implement the plan. Dr. Golab is retiring later this year after nine years with JCPH. She was asked to give some reflections on what it was like to be "present at the creation" and what makes the College of Population Health unique.
\end{abstract}

It was a dark and stormy night. Well, almost. It was Halloween 2007 when the phone rang. "Can you meet me after work?" said the voice on the other end. "I want to make you an offer you can't refuse."

And that's how my journey into the world of Population Health began.

David Nash, MD, then Chair of JMC's Department of Health Policy, had just come from a meeting with TJU President Robert Barchi, MD, PhD. The University was concluding an intense 2-year strategic planning process. Jefferson was at a crossroads. If it wanted to maintain - and enhance - its reputation as a national leader in health care delivery, it would have to tackle the non-clinical issues that were making delivery increasingly difficult - cost, accessibility, quality, patient safety, medical error, chronic disease management, endof-life care. For the industry in general, and for Jefferson in particular, confronting these issues was crucial to survival. Solving them, however, required a paradigm shift in our way of thinking, a shift that would place wellness and prevention at the core of our mission. As a major academic health center, how should Jefferson respond to this challenge? That was the momentous question Dr. Barchi posed to Dr. Nash on Halloween 2007.

When we met that evening over beer to take up the challenge, it became increasingly clear that the idea of a new school dedicated to what we now so easily refer to as "population health" was the only answer. The visionary in David Nash saw this so clearly. For more than twenty years he and other forward thinking Jefferson leaders like Richard Wender, MD, former Chair of the Department of Family and Community Medicine, had been voices in the wilderness, sending up cautionary tales about these issues to any and all who would listen. People were finally listening, but was a new school feasible? Financially viable? What programs would it offer? Who would teach the courses? Would we find students to fill the seats? Could we convince the traditional Jefferson Establishment to do something that had never been done before, anywhere in the country - establish a school dedicated to population health not public health? Our conclusion: Build it and they will come.

And why did I agree to get involved? Throughout my career I have been involved in designing, building, revamping and rescuing the educational initiatives of various institutions (most likely the reason I was asked to take on this new mission). I am, by profession, a historian, someone who has spent a lifetime studying 19th and 20th century immigration and urbanization and the economic and technological forces that brought these two movements together across the cities of the world. In
Present At the Creation.

Specialized Medical Home for Patients with Spinal Cord Injury

Program Director and Faculty Master of Public Health (MPH).

JCPH Class Night 2016.

Recent JCPH Capstone Presentations 2016..... 7

MATER: Innovative Programs for Maternal Addiction Education Treatment and Research

Telehealth at Jefferson: The Future

of Medicine

Triple Aim Forces Drive Academic Health Systems Growth.

The 25th Annual Dr. Raymond C. Grandon Lecture.....

Planetary Health: Report on the 7th Annual Global Health Conference

\section{Announcements \& Upcoming Events}

Population Health Forums

Improving Outcomes in Underserved Communities ...................................................15

In The News. .16

JCPH Publications.

JCPH at the ISPOR 21st Annual Meeting...... 18

JCPH Presentations 
studying the migration of peoples, I find that each group, each migration, has a pattern, and that these patterns speak volumes. I look for root causes - the social and economic determinants - that propel these movements and determine why they happen, when they happen, and why someone ends up here but not there. I use big data to find the patterns, to secure the information that explains why my grandparents settled on the streets of Chicago rather than Baltimore, Minneapolis, Rio de Janeiro or Sydney. In all these ways, I am not very different from the epidemiologist who uses big data to study the spread of disease and who looks for patterns and causes. I was doing "population health" most of my life but didn't know it.

The beauty of starting something from scratch is that you can take the best practices proven elsewhere and make them your starting point. Like Captain Kirk, our secret mentor, we took our mission very seriously to "boldly go where no one has gone before." If I had to pick five things that make the Jefferson College of Population Health unique - and successful - I would offer the following:

1) One-of-a-kind quality programming in health policy, healthcare quality and safety, applied health economics/ outcomes research and, of course, population health. These stand-alone programs, many of them the first of their kind, aim for depth and real-world applications. Although they build on public health foundations, when we started these programs back in 2007 , they were not seen as part of the established public health education model. (This is the primary reason why we opted not to become a School of Public Health.)

\section{2) Student-focused use of asynchronous} online learning. Recognizing that the audience for our programs would be national, even international, an online format was essential. But we had to fight for it. The Jefferson Establishment initially viewed online learning as easy, insufficiently rigorous, and not up to Jefferson standards. In response, we used best practices identified by the Sloan Consortium and the national gold standard rubric Quality Matters to develop high-end online learning programs with small classes (15 students max) where the emphasis is truly on learning. Ratings in critical outcomes - student satisfaction, student learning outcomes, faculty satisfaction, interaction between faculty and students and students with students - are higher in our online courses than our face-toface classes. Online courses, when done right, create a greater sense of community than the typical face-toface classroom. Our online students tell us this all the time.

3) Distinctive faculty models that stress teacher-scholars and practitioners. Usually, faculty are hired for their content expertise and ability to conduct research and to secure funding for it. Promotion and pay increases depend on it. Their interest and ability to teach are secondary. We flipped this model: In JCPH, faculty are hired for their content expertise but evaluated for their teaching; promotion and raises depend on successful student learning. Following the Boyer Model, we guarantee our teacher-scholars 20\% "protected time" so that they can enhance their classroom teaching with scholarship and practice experience. For our online programs, we rely on practitioners, working professionals who can share their personal experience with our students; they "teach" what they actually "do" in real life. These models, while conducive to real learning, are not the norm now, but will be in the future.

4) Innovative approaches to research that create real-world and real-time laboratories to study population health issues. In collaboration with Main Line Health's (MLHS) Lankenau Institute for Medical Research (LIMR), we established a Center for Population Health Research, directed by our faculty, to study health issues specific to the catchment area serviced by MLHS. In similar fashion, we have inaugurated a second research center through a collaboration with the 1889 Foundation and Conemaugh Health System in Johnstown, PA. While the former will study health issues related to both affluent suburban and underserved urban populations (cancer and diabetes, e.g.), the latter will focus on issues related to less affluent rural populations (e.g., opioid drug dependence).

\section{5) Rethinking student audiences and} redefining "workforce development." Students in our on-site MPH program (30\% of our population) tend to be recent college graduates seeking a fulltime (more or less) student experience that prepares them for first-time jobs/ careers. In contrast, students in our online programs tend to be wellestablished working professionals, most often clinicians and healthcare executives, seeking education to cope with the accelerating changes transforming health care today. In our HQS programs, for example, $52 \%$ of students are over 50 and $87 \%$ are over 40; no one is under 30 .

Just as our academic programming favors established health and healthcare professionals, so does our definition of "workforce development." In our view, population health means putting public health together with healthcare delivery (ending the regrettable schism created by the Welch-Rose Report of 1915). ${ }^{1}$ We take public health principles and practice directly to the medical establishment, both current and future, by encouraging Jefferson medical students to complete an MD and an MPH degree while at Jefferson and by working with medical school leaders to revise their curricula to infuse population health. We do this by offering monthly Population Health Forums, annual Population Health Colloquia, Grandon Lectures, Population Health Academies and other CME/CNE activities aimed at medical and healthcare professionals who otherwise would have no exposure to this material.

In retrospect, back in 2007 there was little argument about the idea of a new school. Everyone agreed the time was right. The controversy was in the name. We were strongly advised not to put Population Health in the title. "The term's a fad." "No one knows what it means." "It will be passé in two years. Jefferson will be a laughing stock." 
Almost ten years later, no one is laughing. If imitation is the sincerest form of flattery, then we've started a trend - or, more aptly, a movement. The Universities of New Mexico and New England have established Schools of Population Health and more are coming soon. Countless others have formed Departments, Centers and/or Institutes that bear the name. Still more have added the term to their programming. We receive calls from around the country asking for help in getting started.

Most important of all, the advance to population health has caught the attention of the public health community - with a vengeance. From every program, department and school of public health in the country to leadership groups like American Public Health Association (APHA), Association of Schools and Programs of Public Health (ASPPH), and the Council on Education for Public Health (CEPH), the dialogue over the meaning and "ownership" of population health has become intense, even combative. We are re-thinking Welch-Rose.

The historian in me likes to think that, in many ways, the Jefferson College of Population Health started it all. Our very presence was disturbing. We threw down the gauntlet and challenged the status quo. Now everyone is trying to find their place again. This, when all is said and done, may be the most important contribution that the Jefferson College of Population Health has made to U.S. health care. Resistance is futile. Live long and prosper!

\section{Caroline Golab, PhD}

Associate Dean for Academic Affairs Jefferson College of Population Health Caroline.Golabajefferson.edu

\section{REFERENCES}

1. Feldscher K. The birth of public health education. March 17, 2015. https://www.hsph.harvard.edu/news/features/the-birth-of-public-health-education/ Accessed August 1, 2016.

\section{Specialized Medical Home for Patients with Spinal Cord Injury}

\section{Introduction}

In 2015, Magee Rehabilitation Hospital (Magee) began offering a specialized medical home for patients with spinal cord injury (SCI). This new clinical paradigm adapts a medical home model of patient-centered care to provide proactive clinical care and coordinate social support services for patients with $\mathrm{SCl}$ recently discharged from inpatient rehabilitation. The goals of the program are to maximize patient health outcomes, prevent medical complications and reduce emergency department (ED) visits and readmissions. This program is supported by Magee and by a three-year grant from the Craig H. Neilsen Foundation, which allocates its funding to support SCl populations.

\section{Background}

Since 1978, Magee has partnered with Thomas Jefferson University Hospital to form the Regional Spinal Cord Injury Center of the Delaware Valley. This federally designated model system of care is one of only 14 in the country to provide coordinated, lifetime care to patients with spinal cord injury. Over the past 5 years, Magee has worked to understand how the concepts utilized to improve outcomes for patients in primary care medical homes could be applied to a population with chronic disability due to neurologic insult. The exploration of new payment models to support outcome-driven health care led us to contemplate the role of insurance providers early in the project's conceptualization. To that end, this project aims to reduce costly medical episodes for patients with $\mathrm{SCl}$ and thereby demonstrate to health insurance payers that proactive care management for this population yields better health outcomes and cost savings. To achieve this, Magee is working with payers to share information and develop a business case and new payment model to support the program's services.

\section{Methods}

As patients progress through their rehabilitation and discharge plans are clarified, potential candidates for Magee's Medical Home are identified. The target population is those patients who are at high risk for developing medical complications due to severity of injury, comorbidities, and socio-economic factors. Patients enrolling in the medical home are also those who will return to the community and who will access Magee's outpatient clinic. Informed consent is obtained from participants during inpatient rehabilitation to enable the exchange of health outcome data with payers. Patients can decline to participate in the medical home. Upon enrolling, patients are introduced to the medical home care team which consists of a physiatrist, a certified rehabilitation nurse, a clinical pharmacist, and a social worker. Prior to discharge, the inpatient team performs a face-to-face hand-off with the medical home care providers. The physiatrist and pharmacist perform a thorough medication reconciliation and the pharmacist provides to the patient detailed medication instructions and an easy-to-follow medication schedule. When possible, the pharmacist obtains needed prior authorizations for medications, and patients are discharged with a 30-day supply of medications.

Medical home team members call the patient frequently, as needed, after discharge to help identify potential, emerging medical complications and to ensure that all questions related to care and services are answered. During these calls, the team confirms that equipment, supplies, and services have been received and are functioning well. Clinical guidance is provided and support services are coordinated for each patient. The medical home team is in contact with home nursing and therapy services, primary care clinicians, and medical and surgical specialists to coordinate and discuss patient-specific care needs. Patients are given the phone number to a 24/7 hotline they can call for questions or concerns. The hotline

Continued on page 4 
or infected pressure ulcers, and 1 was caused by thermal burns (Table 2).

is answered by a senior member of the nursing staff, and a physiatrist is on-call for additional consultation.

Patients typically attend their first appointment at Magee's outpatient clinic four weeks after discharge. Additional visits are scheduled every 3 to 6 months and for specific concerns. Specialized providers, such as wound ostomy continence nurses, clinical nutritionists, respiratory services, and urologists are available as needed. Whenever possible, issues are handled by phone, since transportation is often particularly challenging for these patients.

\section{Results}

In the first 15 months of medical home services, 63 patients with SCI were enrolled in the medical home and discharged to the community. Two participants require mechanical ventilation. Thirty-one participants have paraplegia and 32 have tetraplegia. Patient ages range from 14-90 years old (Table 1).

Fourteen patients had 16 all-cause readmissions since the start of the project. Five of these readmissions were for reasons unrelated to $\mathrm{SCl}$, and 2 of these patients died. Of the $11 \mathrm{SCl}$-related readmissions, 6 were for urologic issues, (primarily urinary tract infections), one related to a potential bowel obstruction, 3 related to worsening
Twenty-two patients had 28 ED visits, and 14 of those visits resulted in readmissions noted above. Of the remaining 14 ED visits, 4 were not related to the patient's $\mathrm{SCl}$. Of the $10 \mathrm{ED}$ visits that were related to $\mathrm{SCl}$, 6 were urologic in nature and the others were varied. The medical home team proactively resolved many issues that may have otherwise resulted in readmissions and ED visits, including: bowel impaction, noncompliance with medication, unsafe housing/homelessness, domestic abuse, challenges accessing medical specialists, challenges managing comorbidities (such as monitoring blood glucose levels), challenges obtaining medication refills due to financial or other barriers, inadequate nutrition, and respiratory complications.

\section{Discussion}

Although early in the project, $22 \%$ of the individuals have been readmitted to date, which is well below available comparative figures for similar patient populations (approximately $36-45 \%$ ). ${ }^{1,2}$ Literature is scant related to ED visits. By interceding early and providing timely and appropriate care, the medical home team has helped patients avoid hospital readmissions and ED visits. These proactive clinical and support services are not reimbursable via a traditional fee-forservice payment model. For this reason, the concomitant work with payers to develop a new payment model that meets the needs of the patient, the payer and the provider will be necessary to continue the medical home's services beyond the grant term.

\section{Conclusion}

The SCI Medical Home at Magee Rehabilitation Hospital is a proactive and multi-professional project that is yielding promising, early results. Though the current project is limited to the $\mathrm{SCl}$ population, Magee is exploring broadening medical home services to include patients with other disabilities. In a collaborative demonstration project with Inglis and other partners, Magee is in the process of admitting to the Medical Home persons with a variety of disabilities who are transitioning from longterm care at Inglis House to independent living at Inglis Gardens at Belmont.

\section{Mendel Kupfer, MD \\ Attending Physiatrist \\ Magee Rehabilitation \\ MKupferamageerehab.org}

\section{Marci Ruediger, PT, MS}

Director of Performance Excellence

SCl Medical Home Project Director

Magee Rehabilitation

MRuedigeramageerehab.org

Norah V. Dixon, MA

Grants Manager

Magee Rehabilitation

NDixonamageerehab.org

\section{REFERENCES}

1. Dejong G, Tian W, Hsieh C-H, et al. Rehospitalization in the first year of traumatic spinal cord injury after discharge from medical rehabilitation. Arch Phys Med Rehab. 2013;94(4);S87-S97. http://www.archives-pmr.org/article/S0003-9993(13)00037-3/fulltext. Accessed June 4, 2016.

2. Skelton F, Hoffman JM, Reyes M, Burns SP. Examining health-care utilization in the first year following spinal cord injury. J Spinal Cord Med. 2015;38(6):690-695. http://www.tandfonline.com/doi/full/10.1179/2045772314Y.0000000269. Accessed June 4, 2016.

\begin{tabular}{|c|c|c|}
\hline \multicolumn{2}{|r|}{ Participant Characteristics } & Overall $(\mathrm{N}=63)$ \\
\hline \multirow{2}{*}{ 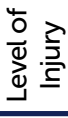 } & Tetraplegia total (includes 2 on ventilators) & $32(51 \%)$ \\
\hline & Paraplegia & $31(49 \%)$ \\
\hline \multirow{4}{*}{ 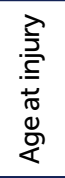 } & $14-29$ & $28(44 \%)$ \\
\hline & $30-49$ & $9(14 \%)$ \\
\hline & $50-69$ & $18(29 \%)$ \\
\hline & $70+$ & $8(13 \%)$ \\
\hline \multirow{5}{*}{ 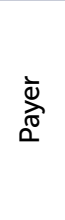 } & Medicare (includes 5 dual eligible Medicare/MA) & $16(25 \%)$ \\
\hline & Medicaid & $12(19 \%)$ \\
\hline & Commercial & $32(51 \%)$ \\
\hline & Worker's comp & $2(3 \%)$ \\
\hline & Self-pay & $1(2 \%)$ \\
\hline
\end{tabular}

Table 2 - Primary Outcomes \begin{tabular}{l|l} 
Participant Outcomes & Overall $(\mathrm{N}=63)$
\end{tabular}

\begin{tabular}{|l|c|}
\hline Total Patients with readmissions & $14(22 \%)$ \\
\hline Total readmissions (includes 2 planned readmissions) & 16 \\
\hline Hospitalizations related to SCl & 11 \\
\hline Patients with ED visits & $22(35 \%)$ \\
\hline Total ED visits & 28 \\
\hline ED visits that resulted readmissions & 14 \\
\hline ED visits related to SCl & 19 \\
\hline
\end{tabular}




\section{Program Director and Faculty Master of Public Health (MPH)}

Jefferson College of Population Health (JCPH), the first school of its kind in the country and one of six colleges of Thomas Jefferson University, a major academic health center located in Philadelphia, PA, is seeking a highly experienced public health professional to serve as Program Director for its CEPH (Council of Education for Public Health) accredited Master of Public Health (MPH) degree program. Along with Directors for the College's other academic offerings in population health, health policy, healthcare quality/safety and applied health economics and outcomes research, the Program Director for Public Health is a key member of the Academic Leadership Team of the College.

The Program Director is responsible for the curricular integrity and instructional quality of the College's MPH, Public Health Certificate and dual degree programs in medicine (MD/MPH; DO/MPH), pharmacy (PharmD/MPH), law (JD/MPH) and social work (MSS/MPH). This oversight includes curricular planning, implementation, and evaluation; Clerkship (practicum) and Capstone (Integrated Experience) projects; recruitment and supervision of full and part-time faculty; and student recruitment. The Director oversees development of College scholarship, service, continuing education and workforce development initiatives related to public health research and practice, both within the University and the larger community, and serves as the College's primary program representative to the Association of Schools and Programs of Public Health (ASPPH).

The successful candidate will hold faculty rank commensurate with their academic qualifications and is expected to teach courses in the public health program, supervise Capstone projects, engage in scholarship that leads to peer-reviewed presentations and publications in the national arena, and serve on various College and University committees.

The ideal candidate will hold a doctoral degree (DrPH or PhD) in public health or a public health-related field, present a portfolio of demonstrated research/ scholarship and have $10+$ years of experience in teaching/curriculum development and public health practice.

The MPH Program Director reports to the $\mathrm{JCPH}$ Associate Dean for Academic and Student Affairs.

\begin{abstract}
To apply for this position, please send a curriculum vitae including a list of three professional references by e-mail to Caroline Golab, PhD, Associate Dean for Academic and Students Affairs and Chair of the MPH Program Director Search Committee at caroline.golab@jefferson. edu. Additional information about the Jefferson College of Population Health and its MPH Program can be found at Jefferson.edu/PopulationHealth.
\end{abstract}

\section{JCPH Class Night 2016}

Every year prior to commencement, JCPH celebrates Class Night to acknowledge and honor the achievements of students who earn a Master's degree and graduate in the current academic year. This year's Class Night also included recognition of those who received a graduate certificate in Operational Excellence. Open to family, friends, and colleagues, Class Night also provides opportunities to recognize outstanding students, faculty and staff.

The Distinguished Student Award was presented to Karie Youngdahl, a graduate of the MPH program. Karie was recognized for her consistent outstanding dedication to public health and academic achievements. Karie is Director of HistoryofVaccines.org and Special Digital Projects at the The College of Physicians of Philadelphia and is the project director and author of the nationally recognized "The History of Vaccines" booklet that was published in 2013. "Predictors of Human Pappilomavirus Vaccination Series Completion in Philadelphia Adolescents" was the focus of her capstone presentation. Karie also recently received the Outstanding Student of the Year Award by the College of Physicians Section on Public Health and Preventive Medicine.

Philip Manasseh was presented with the Distinguished Capstone Project in recognition of his work on "Barriers and Facilitators to Cervical Cancer Screening among Iraqi Refugees Resettled in Philadelphia: A Qualitative Analysis of Patient and Provider Perceptions." The purpose of Philip's project was to not only identify barriers to cervical cancer screening among recently resettled Middle-Eastern refugees, but to recommend potential solutions.

Student access to practical, real-life professional experiences play an important role in public health programs. JCPH is fortunate to work with a number of outstanding organizations that support the MPH clerkships. This year JCPH presented the Distinguished Clerkship Sponsor to the

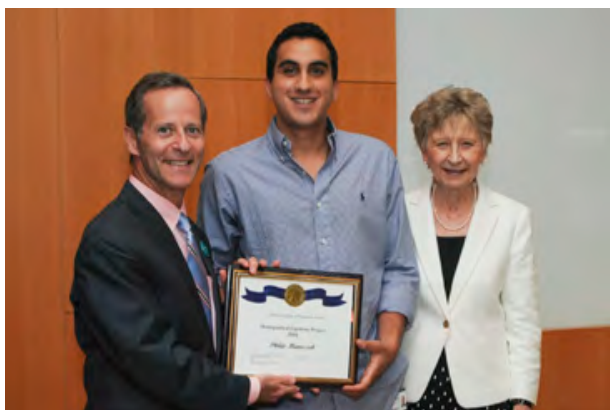

Philip Manasseh with Dr. Nash and Dr. Golab

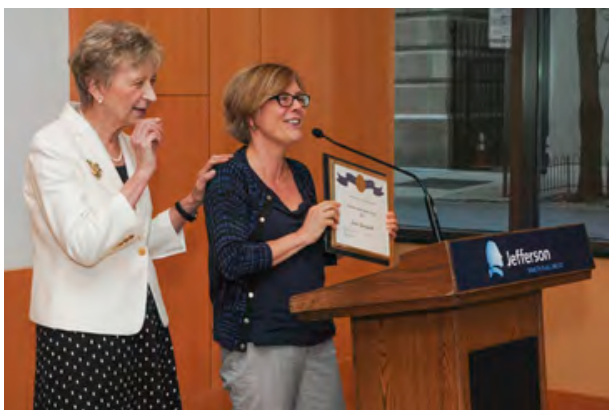

Karie Youngdahl with Dr. Golab

Continued on page 6 
post-master's work in Environmental Sciences at Drexel University.

\section{Jefferson Center for Urban Health}

Under the leadership or Dr. Plumb and Dr. Brawer, the goal of the Center is to improve the health status of individuals and targeted communities through a multifaceted initiative.

Dr. Speakman presented the James B. Erdmann, PhD Student Award for Excellence in Interprofessional Education and Collaborative Practice to MPH student April W. Smith. This award is given to Thomas Jefferson University students whose efforts have positively demonstrated impacted the institution and its interprofessional education programs.

Every year $\mathrm{JCPH}$ recognizes the exemplary contributions of faculty. Richard V. Pepino, MSS, MS, was this year's recipient of the Award for Teaching Excellence. Rich has been a mainstay of our public health program since 2011, when he first taught PBH 507: Fundamentals of Environmental Science to our public health students. He has been enlightening them ever since about both the wonders and hazards of the environment in our daily lives. JCPH is not the first or only institution to recognize Professor Pepino's exceptional teaching skills: Drexel University recognized him with its Laura S. Campbell Distinguished Teaching Award in 2005, and in 2006 Franklin \& Marshall College, Lancaster, PA recognized him with its Most Influential Professor Award for Natural Science.

Rich Pepino has always been interested in studying the environment and educating people about its impact on health. $\mathrm{He}$ is very committed to establishing sound public policies when it comes to our health and the environment we live in. Rich holds an A.B. in biology from LaSalle University and two master's degrees from Villanova University - one in biology and one in Science Education; he has also completed

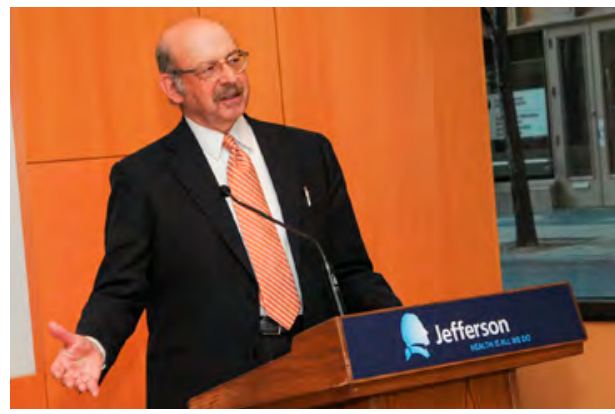

Richard Pepino
Rich discovered his enjoyment and passion for teaching back in the ' 60 s and '70s when he began his career by teaching high school chemistry for ten years, mostly at Malvern Prep and Penn Charter. After teaching high school, Rich moved to the U.S. Environmental Protection Agency ("EPA") in its Region III Philadelphia office, where he worked from 1978 to 2006 , serving as Director, Office of Environmental Programs, for 11 of those 28 years. During this time he also directed the EPA Office of Watersheds, directed strategic planning for environmental efforts in our region, and served as a representative to the U.S EPA Working Group on Emerging Pathogens. When he retired from the EPA after 28 years, he devoted his efforts to directing the Public Policy Program at Franklin \& Marshall College in Lancaster, PA. During his long career, and reflective of his commitment to environmental education, Rich has taught students at Cabrini College (29 years), Drexel University (21 years), and the University of Pennsylvania (13 years).

In addition to Jefferson, Rich continues to teach at Penn where he coordinates the prestigious Benjamin Franklin Scholars Program for Academically Based Community Service Education in the Earth \& Environmental Science Department. He also serves as a Deputy Director in Penn's Center of Excellence in Environmental Toxicology, where, with research funding from the National Institute for Environmental Health Sciences, the Commonwealth of Pennsylvania, and the City of Philadelphia, he provides experiential opportunities to undergraduate students to study the impact of toxic substances in 7 communities. Rich has contributed to multiple peer-reviewed publications illustrating both his concern about the impact of the environment on our health and his advocacy to establish sensible and

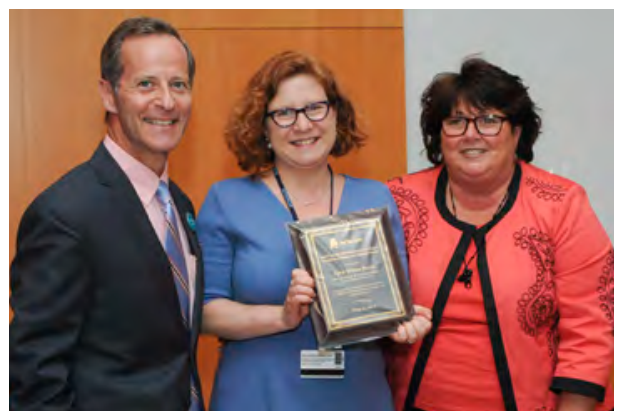

April Smith with Dr. Nash and Dr. Speakman

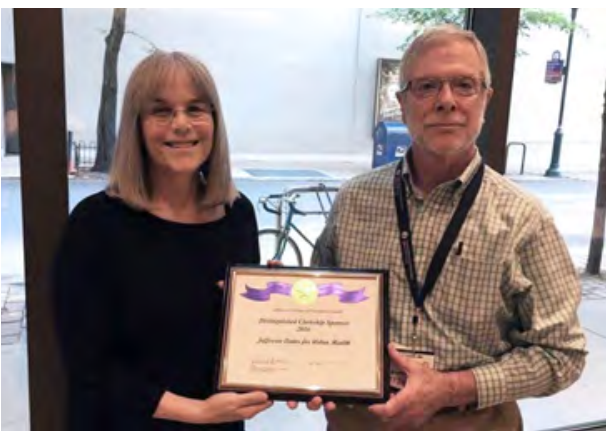

Dr. Brawer and Dr. Plumb

sustainable policies with respect to this issue. One example is his 2014 article in the Journal of Community Health, written with colleagues in response to activities in Pennsylvania, entitled "Fracking: Citizens' Concerns Regarding the Economic, Environmental, Health and Social Impacts of Unconventional Natural Gas Drilling Operations."

Many factors have made Rich Pepino such a successful teacher and his courses so memorable, characteristics that were constantly mentioned and appreciated by his students: first, he likes to tell stories, and second, he encourages class discussions. Stories, we know, are perhaps the ultimate teaching tool because we tend to remember them and we can relate to them. And class discussions, in the hands of a master like Rich Pepino, are an excellent way to encourage critical thinking and to achieve retained learning.

Here is what students had to say about his storytelling and class discussions:

"Your anecdotes from the field" were great and so was your "sense of humor."

"You are great at teaching through storytelling which keeps me interested and also helps me to remember the lectures."

"I liked the discussion aspect of the course and the willingness to engage students and explore a variety of viewpoints."

Perhaps this student gave the best summary of the reasons for his success: "Professor Pepino is a wonderful, engaging and charismatic instructor. I totally dug this class. He possesses a mastery of the subject matter and an innate ability to engage students."

On a more personal note, Rich is a native Philadelphian who grew up in West Philadelphia's Overbrook neighborhood. 
He has 4 siblings and he is 20 years younger than his oldest sibling. His brother, Alfred, is a proud graduate of Jefferson Medical College. He and his wife, Carmella, have been married 44 years, and they have 3 wonderful children, all of whom have careers in education, and 5 grandchildren who keep them constantly active and enthusiastic about life. "Teaching at Jeff has been a wonderful experience," says Rich. "The students are delightful and respectful. I try not to over teach, but rather encourage the students to explore the topics that most interest them along the way. Today's students are just so bright. I find being the facilitator is a more critical role than the prescriptive learning style that I grew up with."

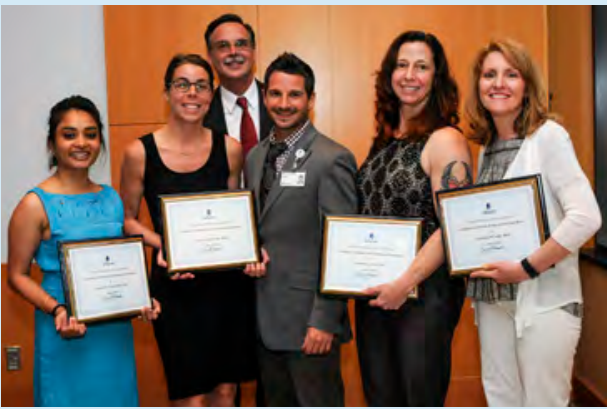

Graduates of the Certificate Program in Operational Excellence with Dennis R. Delisle, SCD, MHSA, FACE, Adjunct Assistant Professor, JCHP (center). Left to right: Kamini Patel, Katie Kennedy, Robert Bartosz, Cynthia Line, and Kathleen Jaffe.
Graduate Certificates in Operational Excellence were awarded to:

Jude Andrews, RN, BSN, OCN

Robert Bartosz, MHA

Kathleen Jaffe, MSN

Katie E. Kennedy, MPH

Cynthia L. Line, PhD

Kamini Patel, MSN, MBA

Cathy Ricker, MS, RN, LDN

Lawrence D. Ward, MD, MPH, FACP

\section{Recent JCPH Capstone Presentations}

Click on capstone titles to access presentations. All JCPH capstones can be found on Jefferson Digital Commons.

\section{Master of Public Health}

Ecological and GIS Analysis of Climate Indicator with Leading Causes of Death. Randy Aviado

Increasing Awareness of Alzheimer's Disease and Related Dementias in the African American Community in the Delaware Valley Region. Jameice DeCoster

Attitudes Toward Interprofessional Collaboration: How Team Dynamic Affects Patient Care in Out Patient Palliative Care-A Provider Viewpoint. Nicole Fernandez

Knowledge and Attitudes of the Emergency Medical Services System in Portsmouth, Dominica: A Study of Adults not Affiliated with the Health Care System. Laurena N. Fotsing

Integrating Resources for Managing Childhood Obesity in the Primary Care Setting: A Needs Assessment. Samareh Hill, MD

Barriers and Facilitators to Cervical Cancer Screening Among Iraqi Refugees Resettled in Philadelphia: A Qualitative Analysis of Patient and Provider Perceptions. Philip Manasseh
Barriers to Utilization of Mindfulness Classes in Underserved Populations. M. Miyori Paris

Association Between Oral Health Literacy and the Oral Health Status Among Diabetic Patients. Deepika Ramachandran

Evaluating The Decision Making Process of Pediatricians' Recommendations for First Complementary Foods in Infants. Gretchen Schmoyer

What Barriers to Treatment and Recovery Do LGBT Individuals with Alcohol Use Disorder Face in Inpatient Treatment? April W. Smith

Journey Through the Preparatory Phases to Baby-Friendly Designation in an Urban Community Hospital. Brittany Wright, CHES, CLC

Predictors of Human Papilloma Virus Vaccination Series Completion in Philadelphia Adolescents. Karie Youngdahl

\section{Master of Science in Applied Health Economics and Outcomes Research}

The Clinical and Economic Impact of Tyrosine Kinase Inhibitor

Non-adherence in CML Patients within a US Integrated Healthcare

System. Amir Aminimanizani, PharmD

\section{Master of Science in Healthcare Quality and Safety}

Five Hundred Sets of Eyes: Improving Patient Safety Incident Reporting by Resident Physicians. Michael Kantrowitz, DO.

Developing an Effective Care Coordination Model that Can Be Utilized for Multiple Patient Populations across a Large Provider Network. Megan Musick 


\section{MATER: Innovative Programs for Maternal Addiction Education Treatment and Research}

Opioid dependence among pregnant women is a pressing public health issue. It is estimated that of the $4 \%$ of pregnant women who report using nonprescription drugs prenatally, opioids rank second, following marijuana, as the drug most commonly used. ${ }^{1}$ Mothers with opioid use disorder face a multitude of barriers to their recovery and successful parenting, including unemployment, incarceration, and physical and mental health problems. ${ }^{2}$ The response to the opioid use epidemic has been focused towards prevention, medications to combat overdose, and medication and non-medication assisted treatment of the substance use disorders.

Within the Jefferson Health system, treatment efforts extend to the past 40 years. During the 1960's, women with opioid dependence largely avoided prenatal care for fear their child would be taken away from them. As a result of the growing need, and lack of services to treat infants and mothers affected by opioid dependence, Loretta Finnegan MD, a neonatologist at Philadelphia General Hospital, established the Family Center outpatient clinic in the early 1970's, through grant funding from the National Institute on Drug Abuse (NIDA), the state and city. The clinic noted a decrease in premature delivery from $48 \%$ (prior to Family Center inception) to $18 \%$ in just a few years. In 1976, Family Center moved from Philadelphia General Hospital to Thomas Jefferson University Hospital. A decade and a half later, My Sisters Place, a comprehensive, medically monitored short- and long-term residential treatment program, was established by Karol Kaltenbach, PhD through a NIDA demonstration project grant.

Both Family Center and My Sisters Place were established to meet the continuously growing need for services for mothers with opioid dependence. They are both integrated services of the Division of MATER (Maternal Addiction Treatment Education and Research), a division of the Department of Obstetrics and Gynecology, Sidney Kimmel Medical College at Thomas Jefferson University. Diane J. Abatemarco, PhD, MSW is the Director of MATER, and has a significant academic research agenda for this vulnerable population. MATER has a history of serving as a national and international model opioid treatment center and is supported by federal, state, city funds, and private foundations.

Women enter these programs via several referral routes. Currently, the most common referral route is through the emergency department at Thomas Jefferson University Hospital. Pregnant women with opioid use disorder present at the emergency room and are admitted for inpatient stabilization on methadone over several days. A nurse and peer specialist from MATER meet with women being stabilized to assess their need for either outpatient or residential treatment and begin the intake process to the appropriate program. MATER also receives referrals from other treatment programs, the criminal justice system, and Philadelphia's extensive network of crisis response centers. To be admitted to our programs, women must be at least 18 years old, pregnant or parenting, and meet the Pennsylvania Client Placement Criteria for one of the levels of treatment offered for substance use disorders. Women who meet criteria for outpatient or intensive outpatient treatment are inducted into Family Center, and women who meet criteria for short- or long-term medically monitored residential treatment go to My Sister's Place. Payment for services at Family Center or My Sister's Place are covered by Medical Assistance plans and sliding fee scales are available.

Family Center is a comprehensive women-centered outpatient treatment program for women with substance use disorders who are pregnant, parenting, or working towards reunification with their child. The program is licensed by the Pennsylvania Department of Drug and Alcohol Programs to provide methadone and buprenorphine medication assisted treatment (MAT) as well as drug-free treatment. All women at Family Center receive comprehensive psychological and medical services including: individual, group, and family psychotherapy, psychiatric care, 12-step meetings, methadone anonymous meetings, nutrition education, mindfulness-based stress reduction, peer support from a certified peer specialist, case management including coordination of prenatal care and pediatric care, smoking cessation assistance, HIV testing and counseling referral, parenting education, parent-child activities, child care and education, child developmental screening and referral, and art therapy. While the majority of admissions to Family Center are pregnant women, all women are welcome to receive Family Center's care after the end of their pregnancy; some women transfer to clinics closer to their homes or leave treatment altogether.

My Sister's Place is a medically monitored short- and long-term residential treatment program serving up to 22 mothers. Women typically receive treatment at My Sister's Place for 6 months to one year, depending on their progress. Women may bring up to three of their children aged 0-6 years to reside at My Sister's Place. The number of children admitted is determined on a case-by-case basis, depending on space available. Women receiving treatment at My Sister's Place receive the same range of comprehensive services as women in outpatient treatment at Family Center, provided for more hours per week and at lower client-to-staff ratios. Women at My Sister's Place also receive daily living skills training, financial management assistance, medication management, and on-site early intervention services for children. Women are referred off-site for GED, literacy, and vocational training. When women no longer require the intensive treatment that the residential clinic provides, they may transition to Family Center's outpatient care or to other programs in the city.

Considering the public health impact of the opioid epidemic, MATER is in a unique position as it is also the site for a growing research portfolio. The Division is currently the site for a federally funded grant by the Department of Health and Human Services, Administration for Children and Families (ACF), Children's Bureau entitled, "Practicing Safety Mindfulness Project for Mothers in Drug Treatment." This grant aims to prevent the toxic stress imparted on the developing child that is often seen 
in families with substance use issues. The components of this grant include: 1) a Mindfulness-Based Parenting Intervention for mothers at Family Center, which was recently nominated for an innovation award by the Scattergood Foundation, 2) a quality improvement aspect entitled "Practicing Safety" at Jefferson Pediatric clinic, and 3) enhanced case management between the social worker at Jefferson Pediatric clinic and the case manager at Family Center. Outcomes level data for this grant include: examining the impact of the intervention on parenting; parenting stress; mindfulness; child wellness visits; and adherence and timeliness of pediatric immunizations. MATER research includes the impact of a mindfulness-based childbirth intervention on preterm birth, interventions targeting tobacco cessation, as well as epidemiologic analyses on neonatal abstinence syndrome. MATER is also conducting research developing novel behavioral interventions to reduce use of tobacco and illicit drugs among pregnant, methadone-maintained women.

MATER continues to evolve and adapt to the population it services, honoring the women and their commitment and journey to recovery through its outpatient and residential services, as well as its research. It has been internationally recognized as a premier treatment model due to the founding leadership and decades of work of Drs. Finnegan and Kaltenbach. With Dr. Abatemarco's leadership, MATER is poised to expand mindfulness throughout its treatment approaches with its clients, continue to evaluate and improve the services it offers, and grow its research feeding back results to the research community and the mothers it serves.

For more information on MATER, contact Diane J. Abatemarco, PhD, MSW at Diane.Abatemarco@Jefferson.edu. For more information on the "Practicing Safety Mindfulness Project for Mothers in Drug Treatment", please contact the author at Meghan.GannonaJefferson.edu.

\section{Meghan Gannon, PhD, MSPH}

Project Coordinator

Department of Obstetrics and Gynecology

Sidney Kimmel Medical College at

Thomas Jefferson University

Meghan.GannonaJefferson.edu

\section{REFERENCES}

1. Wendell AD. Overview and epidemiology of substance abuse in pregnancy. Clin Obstet Gynecol. 2013;56(1):91-6.

2. Skinner ML, Haggerty KP, et al. Opiate addicted parents in methadone treatment: long term recovery, health and family relationships. J Addict Dis. 2011; 30(1):17-26

\section{Telehealth at Jefferson: The Future of Medicine}

There is an old saying that "what goes around comes around," and no statement is truer when it comes to healthcare. Years ago, it was common for physicians to make "house calls" to visit sick patients in their own homes. However, as more patients needed healthcare, it became inefficient for providers to visit so many different homes. Instead, clinicians switched to providing healthcare in a central location, with patients coming to them. With the help of technology, receiving healthcare is now efficient for both the provider and the patient-patients no longer have to trek to the hospital, and clinicians can continue to see patients without leaving their central location.

One new way for patients to see providers is through JeffConnect, a telehealth service launched in June 2015 that offers video visits with a Jefferson healthcare provider via web or mobile application. Currently, Jefferson offers three virtual services through JeffConnect: OnDemand Virtual Care Scheduled Online Visits, and Remote Second Opinion.

Through On-Demand Virtual Care, Jefferson emergency medicine physicians are available 24/7 to provide care. Because of Jefferson's geographic location, physicians are licensed to provide care in Pennsylvania, New Jersey, and Delaware. Physicians have treated patients as far as north as New Brunswick, New Jersey, and as far south as Smyrna, Delaware. After "seeing" the patient, the telehealth doctor is able to send a summary of the visit to the patient's primary care doctor, facilitating seamless communication and care coordination. This service was first piloted with Jefferson employees, and opened up to the general public in September 2015.

Scheduled Online Visits allows Jefferson healthcare providers to have follow-up appointments with their patients virtually, as an alternative to having patients come back to the office in person. The providers are each placed in online departments based on their practices and schedule appointments the same way they would for in-person visits. With these services, patients are given more options and additional methods to access the care they need.

Remote Second Opinion consultations are available in certain specialty areas through Thomas Jefferson University Physicians. This includes telephone or video consultations to individuals who are looking to receive a second medical opinion. After reviewing test results and the medical records, the Jefferson specialist is able to provide a recommendation to the individual and their treating physician without the need for them to travel to Philadelphia. The ability to consult a healthcare provider without having to take time off from work, to travel into the city, or to pay for parking, is significant to patients.

Since launching the service, JeffConnect has been a success as evidenced by high patient satisfaction rates of $98 \%$ and 92\% for On-Demand Virtual Care and Scheduled Online Visits, respectively. As an institution, Jefferson is moving towards a model that incorporates shared decision making between the patient and provider. Instead of having physicians decide where and when patients can get care, patients are able to have more control and get care on their own accord. Many patients are excited about the concept-

Continued on page 10 
the average time of a JeffConnect visit is about 10 minutes, and to see a clinician and receive care within the comfort of their own home is a huge benefit. When the occasional technology glitch occurs, Jefferson healthcare providers are able to continue the telehealth visit via phone call and immediately address any health problem that the patient may have.

As JeffConnect services grow and patient satisfaction rises, Jefferson healthcare providers are becoming more engaged with telehealth services. In its first month of operation in June 2015, Jefferson physicians conducted approximately 15 visits. Eleven months later, the number of overall visits increased to approximately 430. As of June 2016, the number of JeffConnect visits is approximately 3000. Jefferson healthcare providers are learning how to conduct telehealth visits and properly exhibit an engaging "webside" manner. For example, clinicians demonstrate creativity in how they conduct a physical exam-by asking the patient to perform certain tasks such as walking around the room or pushing on certain areas of their body. This allows providers to evaluate the patient virtually and engage the patient with questions and education. "It has been both challenging and rewarding to transform a conventional, three dimensional, in-person visit into a virtual encounter with a patient. Involving the patient in the exam has been a requisite part of this process. We have been able to virtually guide a patient through an abdominal exam for example, and gain valuable and relevant clinical information based on their responses," explains Dr. Roger Band, Vice Chair of Strategic Outof-Hospital Initiatives.

The ability to improve access to care may help to prevent patients from waiting until they are so sick that they have no other alternative but to go to the ED. Through Jefferson's telehealth services, patients can seek care earlier, before complications occur and a higher level of care is needed. Telehealth will reduce health costs-by having a \$49 on-demand virtual visit, patients will avoid an expensive trip to the ED, allowing once overcrowded emergency departments to have fewer patients walking through the door.

Of course, not all patient visits are optimal for telehealth services. JeffConnect is best used under certain circumstances. Patients with routine follow-up appointments for chronic disease management or medication updates are ideal for telehealth. For example, patients with chronic asthma are able to have JeffConnect visits with their pulmonologists to discuss general concerns and symptom management. Pulmonologists are able to observe patients administer a dose of medication using their inhalers and provide guidance on medication effectiveness.

Healthcare is undergoing unprecedented changes and Jefferson is leading the way, focusing on redesigning the way healthcare is delivered. In this transformation, Jefferson is utilizing telehealth technology as a tool pursuing the three dimensions of the Triple Aim: improving patient access and experience of care, while at the same time lowering healthcare costs, and improving the health of populations. Through our telehealth services, Jefferson is able to provide comprehensive high quality care to patients when and where they need or want it.

\section{Danica Stone}

Telehealth Project Manager

Jefferson University Hospitals

Danica.Stone@jefferson.edu

\section{Triple Aim Forces Drive Academic Health Systems Growth}

It seems that, across the country, there is an increased acceleration in the pace of community hospitals bonding with academic centers. Our own Jefferson Health System has recently formalized close relationships with 3 local community hospital systems -

\section{Table $1^{3}$}

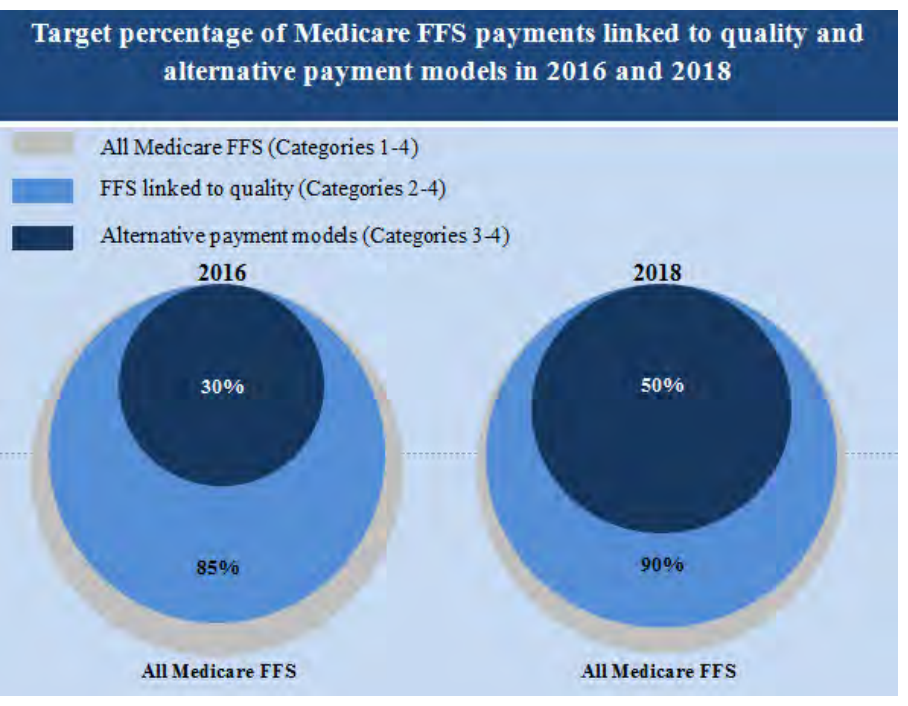

Abington, Aria, and Kennedy. This is being driven, in part, by the need to deliver valuebased care that is based on the Triple Aim of improving the health of populations, improving the patient experience of care (including quality and satisfaction), and reducing the per capita cost of health care. ${ }^{1}$

The Triple Aim approach is firmly positioned at the opposite end of the market spectrum from the fee-for-service, non-coordinated acute care that has historically been the model of health care delivery in the U.S. For hospitals this means shifting from a focus on 'heads in bed' (volume) and working to decrease the length of stay (value). This shift is being driven by the U.S. Department of Health and Human Services ${ }^{2}$ goal of tying an increasing percentage of Medicare payments to quality or value using alternative payment models. This will be occurring in a significant manner for both clinicians and hospitals over the next few years as noted in Table 1.

The CMS Innovation Center supports the development and testing of innovative health care payment and service delivery models. Through a growing portfolio, CMS Innovation Center is testing various payment and service delivery models (Table 2) that aim to achieve the Triple Aim.

\section{Population Health Benefit}

To achieve the CMS objectives of "better care, smarter spending, healthier people" academic health care centers are joining with community hospitals to form a contiguous "hub and spoke" model. This approach supports the Triple Aim 
priorities in the following ways. First, on the population health front, it has the potential to significantly increase the reach of all parties. This increased market share in the community facilitates a focus on innovative population health strategies. These are more easily accomplished when the community hospital is the dominant force in the market, allowing increased investment and partnership with non-traditional healthcare stakeholders such as schools and park programs. Embracing population health as a key strategic initiative may come at too high a cost for most small, hospital-centric organizations. Driving out costs may mean fewer patients, less visits, less relative value units (RVU's). However, expanding the breadth and depth of a system through mergers and acquisitions can serve as a solid growth strategy. Expanding geographic access, creating high-value provider networks of care delivery and investing needed capital to better meet the needs of a community, all serve to grow market share and improve profitability, and thereby allow organizations to further invest in population health strategies.

\section{Quality of Care Delivery}

Second, on the quality of care front, partnering with an academic center of excellence allows the increased use of best practices into these community hospital partners. Many academic health systems have developed detailed protocols based on evidence-based medicine and processes to deliver optimum outcomes. The expansion of these best practices, supported through the use of a common electronic health

\section{CMS Innovation Center Alternative Payment Models}

- Accountable Care and similar care models

- Bundled Payments for Care Improvement

- Primary Care Transformation

- Initiatives Focused on the Medicaid and CHIP Population

- Initiatives Focused on the Medicare-Medicaid Enrollees

- Initiatives to Speed the Adoption of Best Practices

- Initiatives to Accelerate the Development and Testing of New Payment and Service Delivery Models

record and shared clinical informatics has the potential to improve quality of care. Clinical standardization, through programs and processes developed in concert with an academic partner, can reduce clinical variation and places providers in a strong position for value-based payments.

\section{Cost Effective Care}

Third, regarding the need to be even more cost effective in care delivery, these partnerships provide increased economies of scale by reducing operational expenses. One major area of investment and efficiency is information technology. Increasing IT interoperability between disparate systems to support integrated networks and provide seamless care coordination will be a challenge for all organizations seeking to deliver value-based care and realize economies. The combined system typically focuses on identifying a single IT platform with the goal of creating a truly integrated network of care for patients and providers.

All these factors come together to provide these growing systems with the necessary resources to have a greater impact on a larger portion of the population.

\section{Richard G. Stefanacci, DO, MGH, MBA, AGSF, CMD}

Lecturer, Jefferson College of

Population Health

Chief Medical Officer, The Access Group

Richard.StefanacciaJefferson.edu

\section{Terri Schieder, RN, MBA}

Vice President, Clinical Integration

and Transformation

AtlantiCare

Terri.SchiederaAtlantiCare.org

\section{REFERENCES}

1. Berwick DM, Nolan TW, Whittington J. The Triple Aim: care, health, and cost. Health Aff. 2008; 27(3):759-769.

2. U.S. Department of Health and Human Services. Better, Smarter, Healthier: in historic announcement HHS sets clear goals and timeline for shifting Medicare, reimbursements from volume to value. January 26, 2015. http://www.hhs.gov/about/news/2015/01/26/better-smarter-healthier-in-historicannouncement-hhs-sets-clear-goals-and-timeline-for-shifting-medicare-reimbursements-from-volume-to-value.html. Accessed June 4, 2016.

3. Centers for Medicare and Medicaid Services. Better care. Smarter spending. Healthier people: paying providers for value, not volume. January $1,2015$. https://www.cms.gov/Newsroom/MediaReleaseDatabase/Fact-sheets/2015-Fact-sheets-items/2015-01-26-3.html. Accessed June 4, 2016.

\section{WISHING A WARM FAREWELL TO JOHN MELVIN, MD AND KEVIN LYONS, PHD}

Dr. Melvin and Dr. Lyons have served as members of the Population Health Matters Editorial Board for many years and they are both retiring. We appreciate their dedication, commitment, and contributions to the newsletter and we wish them well! 


\section{Submissions Due August 26, 2016}

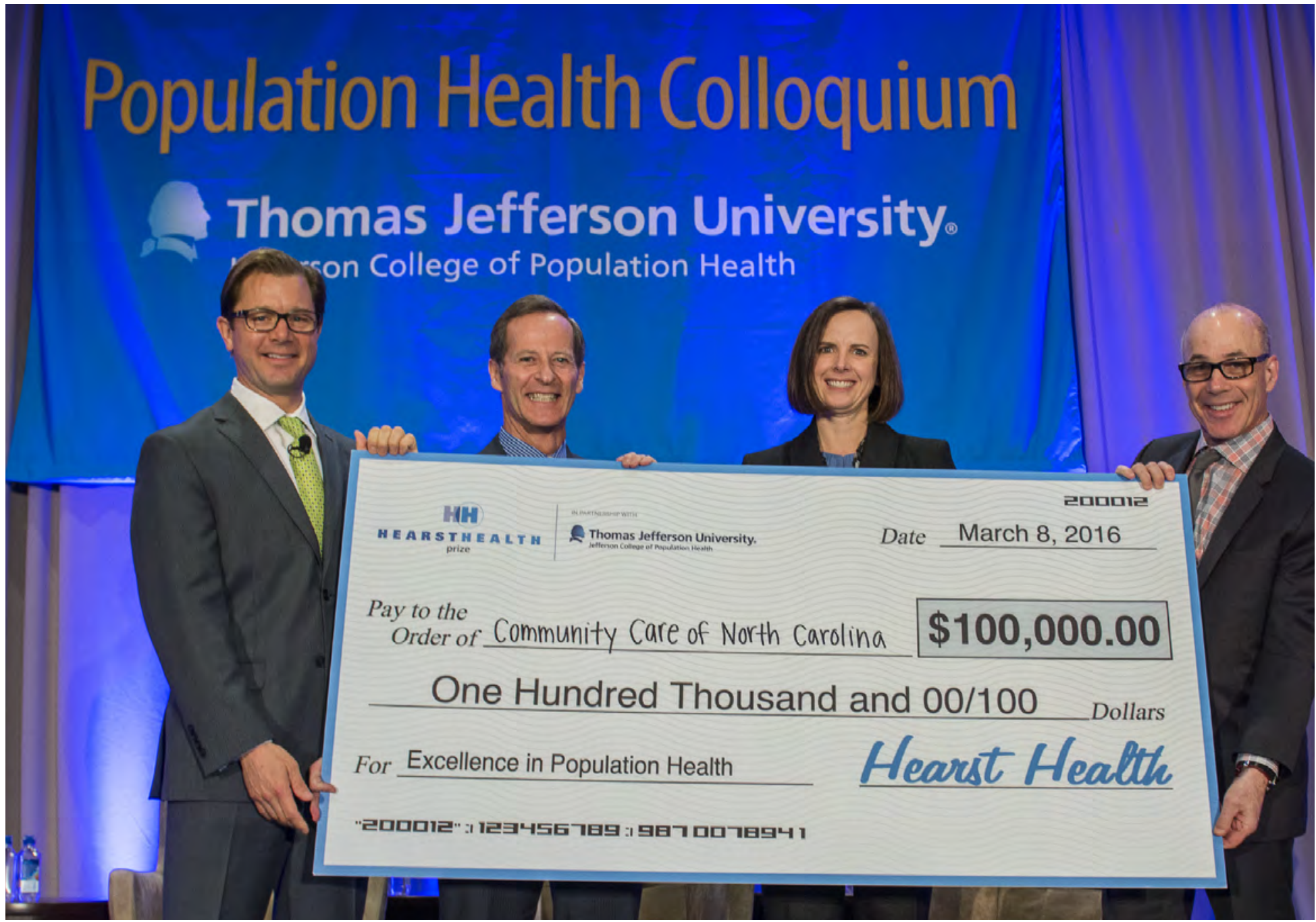

Prior year's award; pictured left to right: Gregory Dorn, MD, MPH, President, Hearst Health; David Nash, MD, MBA, Dean, Jefferson College of Population Health; Annette DuBard, MD, MPH, Chief Health Information Officer \& SVP for Population Health Analytics, Community Care of North Carolina; Stephen Klasko, MD, MBA, President \& CEO of Thomas Jefferson University \& Jefferson Health

\section{$\$ 100,000$ Cash Prize}

in recognition of outstanding achievement in managing or improving population health.

We seek to discover, support and showcase the work of an individual, group, organization or institution that has successfully implemented a population health program or intervention that has made a measurable difference managing or improving population health.
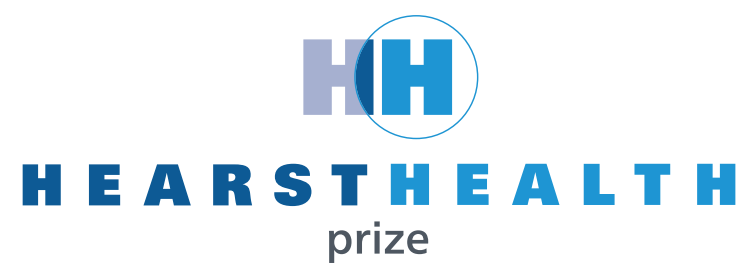

IN PARTNERSHIP WITH

\section{Thomas Jefferson University}

Jefferson College of Population Health

For more information and to submit an entry: www.jefferson.edu/HearstHealthPrize 


\section{The Benefits of Building Scale for Population Health.}

\section{Alan Zuckerman}

Director and Chair, Veralon

\section{John Harris \\ Director, Veralon}

April 13, 2016

\begin{abstract}
Alan Zuckerman is one of the nation's leading health care strategists and has directed the development of advanced strategic and business plans for many top academic medical centers and health systems. John Harris has a wealth of experience in health care that includes founding a healthcare business, running facilities and consulting to hospitals, health systems, ACOs, CINs, IPAs, and health plans. Zuckerman and Harris are directors at Veralon, a transformative healthcare consulting and strategy firm.
\end{abstract}

Mr. Zuckerman began the session by raising the questions of whether or not there are more benefits or deficits to building scale. He then went into an explanation of why scale matters and stated that being "in the middle is difficult." He discussed the need to be somewhat risk-bearing.

The benefits of scale as described by Zuckerman include the following: it enables vertical integration and greater management of the full continuum of care; increases essentiality in the market through contracting leverage, geographic coverage, and quality; increases the ability to cope with declining prices and higher costs, spreads financial risk over a large base; and provides a proper universe of patients to enable "systems of care" and population health efforts to be the most efficient and effective.

Critical success factors necessary for systems to assume a consolidator role are focused on a few key ideas such as integration of health enterprise components and willingness to take a risk; population health orientation; and value drivers. Zuckerman emphasized that aligning internal and external incentives, being concerned about prices and really meaning it, and being able to function in a manner that integrates are very important factors.

Using examples of various health systems, Zuckerman went on to describe primary approaches or models of building scale as: national/international integrator; regional integrator; collaborative integrator; and independent. Regional integration is most common model and the independent model is the least common.

As the presentation shifted to an overview of alignment models, Mr. Harris discussed the continuum of physician and hospital alignment models and the complexities of various networks. "One of the challenges for hospitals and health systems is how to connect with their physicians," explained Harris. Clinically Integrated Networks (CIN) is a way of bringing together a hospital or health system with physicians in order to work on population health, partner with payers, and be rewarded while creating better value.

Harris then discussed potential disruptors and described three types of innovators: revolutionized primary care; empowered physician networks; and app-enabled engagement. Revolutionized primary care has to do with the shift from the old model of care of fee-for-service to the patient care team, a proactive approach with patient engagement and relationship building in which there is reward for value. Empowered physician networks are networks that include physicians and specialties and typically don't include hospitals. "Their effort is to fix care delivery, control referrals, sharing the dollar and savings with the payer... and implementing information technology," explained Harris. Harris describes app-enabled engagement as something that gets in between the patient and the provider and is indicative of the 'consumerization' of healthcare.

It is clear from Zuckerman and Harris that multiple models, such as integrated insurer/ provider; health system; collaborative networks; and physician entities, are competing to execute population health.

The Forum was followed by a special Grandon Society workshop which delved into numerous examples of specific cases of health care systems creating remarkable change. Zuckerman and Harris also discussed the theme of external influence and economic incentives - meaning the challenge of getting physicians to evaluate, self-reflect, with the needed economic stimulus.

In summary, scale is necessary for health systems to be successful in a population health environment, but scale alone is not sufficient.

\section{Training "Clinicians Plus": A New Paradigm of Medical Education.}

\author{
Allan R. Tunkel, MD, PhD, MACP \\ Professor of Medicine and Medical Science \\ Associate Dean for Medical Education \\ Warren Alpert Medical College of \\ Brown University \\ May 11, 2016 \\ Dr. Allan Tunkel of Brown University began \\ his Forum presentation by providing an \\ overview of key problems in the U.S. \\ health care system, such as suboptimal
}

outcomes, misaligned incentives and the issue of those who are either uninsured or underinsured. He went through the historical context of recommendations for improvement, referring to resources such as the Commonwealth Fund, the Institute of Medicine Report, and Triple Aim.

Given this context, Tunkel explained what he refers to as the "Third Science of Medicine" or Health Systems Science. "Ideally, this should complement and integrate with the core disciplines of the foundation of basic science as well as the clinical science taught through all four years of medical school," states Tunkel. Tunkel believes that schools need to make room for this Third Science, which will lead to quality improvement and leadership opportunities and prepare students for working in interprofessional teams.

Continued on page 14 
Tunkel's presentation focused on Brown University's new program in primary care (PC) and population health medicine (PM), a very unique approach to curriculum reform that is the only one of its kind in the country. In existence for three years, the foundation of this 4-year program is that students will obtain a doctor of medicine and a master's of science (ScM) degree in population medicine; an optional tuition-free 5th year is available. Tunkel explained the philosophical approach to this program: the master's program had to be integrated across all four years of the curriculum. The idea is to help students apply classroom learnings to patient populations; the focus is on using systems designs to improve outcomes.

The PC-PM program is designed to train students to become "clinicians plus." The hope is that these students will become clinicians in education, research, and advocacy, and develop a strong emphasis on population focused, generalist medicine. The program includes interdisciplinary and leadership training; a longitudinal integrated clerkship; and scholarship in primary care, population medicine and health policy.
Tunkel hopes that the program has a "halo" effect, meaning that other faculty mentors will jump onto the "population medicine bandwagon" and that it will permeate through other aspects of the MD curriculum. Very important stakeholders of this program are the health care leaders in the region who envision this program as a means to improving healthcare in Rhode Island while fostering research.

Tunkel went on to describe the specifics of the curriculum, including the new courses within the population medicine concentration: Health Systems Science I and II; Research Methods in Population Medicine; Quantitative Reasoning; Independent Study/ Thesis Research; Leadership; Population and Clinical Medicine I and II, and Capstone in Population Medicine.

One feature of this program is the inclusion of leadership curriculum which is experiential, team-focused, integrated, and serviceoriented. Based on the idea that leadership is developmental, Brown's program allows students to build skills and apply core leadership attributes by demonstrating effective communication and critical thinking skills. Managing change in a team environment is also an important aspect of the leadership curriculum. All students will be required to work on a capstone "change" initiative as part of experiential leadership training. This involves identifying a problem and coming up with solutions in collaboration with a team of professionals.

Another interesting aspect of this program is the longitudinal integrated clerkship. This differs from the traditional clerkship in that it includes more inpatient immersion; provides more time in outpatient settings; and uses didactics that are integrated and scheduled across the entirety of the longitudinal model (without block rotations). This helps students to develop relationships with patients, health mentors and families and follow them longitudinally. They are currently piloting this program with 8 third-year medical students.

The early findings of the Brown University's program show that there are no differences in metrics for students applying to the PCPM program compared to the traditional program; additional workload in the PCPM program was not an issue in the first year; and students enjoyed the longitudinal integrated clerkship compared to those students in the traditional clerkship.

\section{What Will It Really Take to Improve Population Health?}

\section{Thomas A. Farley, MD, MPH \\ Health Commissioner \\ Philadelphia Department of Public Health \\ June 8, 2016}

When Dr. Farley was first invited to speak at the JCPH Forum, he was CEO of The Public Good Projects, a non-profit organization that uses advertising messages to combat the nation's pressing social and health problems. Little did we know that Dr. Farley would become Philadelphia's Health Commissioner in Mayor Kenney's new administration! Though just a few months into his new role, Dr. Farley is a big "catch" for Philadelphia. He was Health Commissioner of New York City from 2009-2014, and was known for his innovative public health policies, and advocacy, including making the city's parks and beaches smoke-free, prohibiting price discounting of cigarettes, raising the legal sales age of tobacco to 21 , and capping the portion size of sugary drinks sold in restaurants at 16 ounces. Dr. Farley is author of Saving Gotham: A Billionaire Mayor, Activist Doctors, and the Fight for Eight Million Doctors.
Speaking to a packed house, Dr. Farley began his presentation by discussing the broad population health imperative the federal government's requirement for hospitals to "do" population health. "Despite the fact that there is no broad consensus on what population health means...and even more so I think there is not an understanding of what it will really take to improve population health," states Farley. This presentation is based on his thought process of what is takes to improve population health. Dr. Farley defines population health as a measurable improvement in the health of the entire population.

"We're not in very good shape," Farley explained, as he revealed startling data on life expectancy, health care spending, and leading causes of death in the U.S, this within the context of high costs of health care spending per capita. "If we really want improvement...we have to do something fundamentally different than what we are doing now," states Farley.
"How do we alter our trajectory?" Farley asks. He believes that we have to start by identifying our health problems. Pointing to leading causes of death, our nation clearly has huge challenges in dealing with chronic diseases (i.e. heart disease, lung disease, diabetes, etc.). Thinking through the causes of these conditions, it is important to look at factors that affect health with socioeconomic factors (or social determinants) being the most significant. Other factors include: changing the context, long-lasting protective interventions, clinical interventions, and counseling and education.

Farley has what is refers to as a "simplified" version of determinants of health which include: health care access and quality, behavioral and environmental risks, and social determinants. Unhealthy diet is a behavioral risk that is attributed to the most number of deaths in the U.S. Smoking and high blood pressure are also responsible for a high number of deaths. What this means, explains Farley, is that these deaths are also potentially preventable. 
When referring to social determinants attributed to death, Dr. Farley pleaded with the audience to get a sense of the magnitude of the problem, with individual factors such as low education, low social support, racial segregation and income inequality as being the most influential. Though improving health care access and quality and reducing behavioral and environmental risks are very important, Dr. Farley's overall belief is that the most lives can be saved by addressing social determinants.

Dr. Farley went on to discuss the difficulty in reaching large numbers of people to change behaviors. For example, in Philadelphia it is estimated that approximately 250,000 people are smokers and 375,000 people are obese. This is a challenging problem to deal with on a one-to-one level. Classic policy approaches can be very effective, especially when it comes to smoking. Examples include taxes, smoke-free air laws/policies, marketing restrictions, and minimum age of sale. Healthy eating policies include trans fat restriction, sugary drink tax, and healthier food standards for SNAP.

Farley believes mass media is the least expensive way to reach large numbers of people and he described effective ads impacting health related behaviors. Using New York City data, he explained how media messages create social change. $\mathrm{He}$ showed how the consumption of sugary drinks decreased after specific ad campaigns targeted this problem. Farley emphasized that many social movements in this country have involved policy change and innovative use of mass media.

"If we want to make a measurable improvement in population health, we are going to have to address the behavioral and environmental determinants, that's where the biggest potential payoff appears to be, and then we have to address social determinants...if we want to make

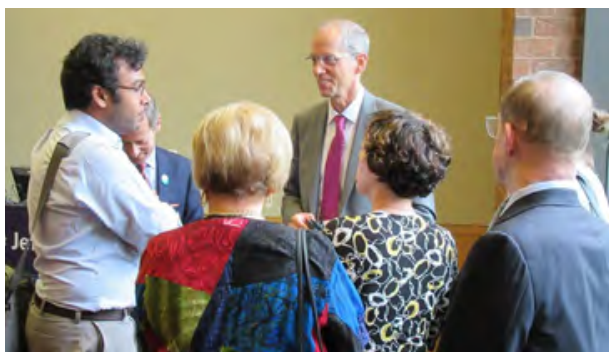

Philadelphia Health Commissioner Dr. Thomas Farley speaks to participants at the Forum.

differences in these determinants, we have to think big," states Farley.

A lively discussion followed, with questions regarding Dr. Farley's past experiences in New York City and the current hot topic of Philadelphia - the sugary drink tax. Later that day, City Council preliminarily approved a 1.5-cent per ounce tax on sugar drinks and diet sodas.

Forum presentations are archived on Jefferson Digital Commons.

\title{
POPULATION HEALTH FORUM "IMPROVING OUTCOMES IN UNDERSERVED COMMUNITIES"
}

\author{
Featuring \\ Garth Graham, MD, MPH
}

President, Aetna Foundation

\author{
September 14, 2016 | 8:30 am - 9:30 am \\ College Building - Herbut Auditorium (Ground Floor) \\ Thomas Jefferson University, 1025 Walnut Street, Philadelphia, PA 19107 \\ Jefferson.edu/PopHealthForum
}

\section{The 25th Annual Dr. Raymond C. Grandon Lecture}

\section{May 12, 2016}

"The Impact of Healthcare on the 2016

Election" was the focus of the 25th Annual

Dr. Raymond C. Grandon lecture. The

keynote presenter was Gail R. Wilensky, PhD,

an economist and senior fellow at Project

$\mathrm{HOPE}$, an international health foundation.

Her expertise is on strategies to reform

health care, with particular emphasis on

Medicare, comparative effective research

and military health care. Dr. Wilensky

provided an excellence overview on ACA,
Medicare, and future policy implications impacted by politics.

In celebration of the 25th Anniversary of the Grandon Lecture, it was an honor to have Raymond C. Grandon, MD in the audience with his wife Doris. Dr. Grandon recently closed his practice after serving patients for 65 years!

For Grandon lecture slides and audio recordings visit: JDC.Jefferson.edu/Grandon

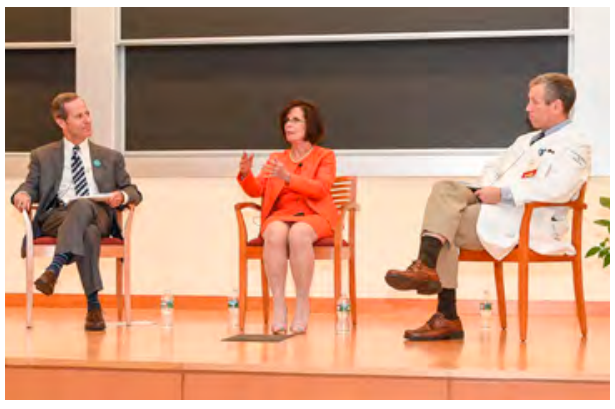

Fireside chat with Dr. Nash, Dr. Wilensky, and Dr. Gregory C. Kane. 


\section{IN THE NEWS}

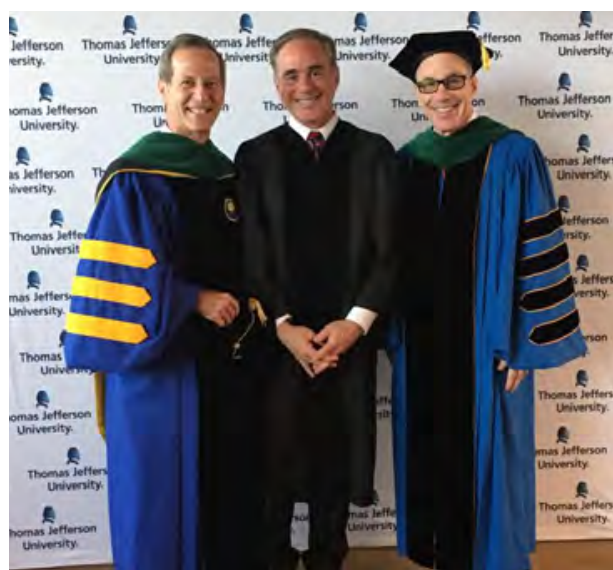

David J. Shulkin, MD, (center) Under Secretary of Health, U.S. Department of Veterans Affairs was the honorary degree recipient at the 2016 Commencement.

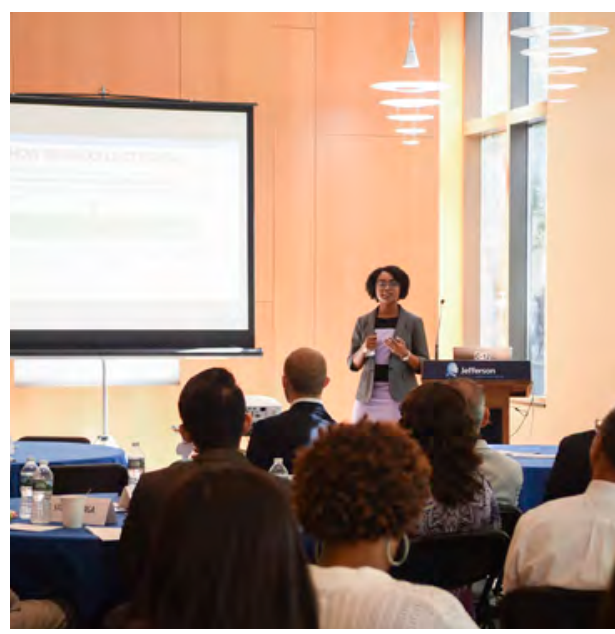

Jacqueline McRae, PharmD (Janssen, Inc.) presents at Fellows Day.

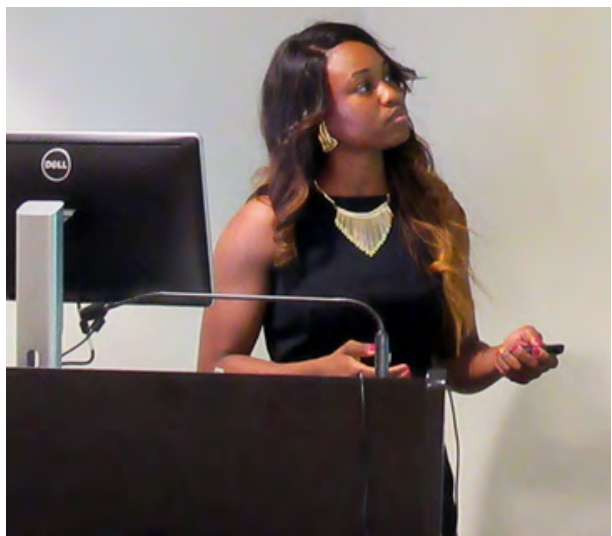

Jameice DeCoster presents her MPH capstone presentation, "Increasing Awareness of Alzheimer's Disease and Related Dementias in the African American Community in the Delaware Valley."

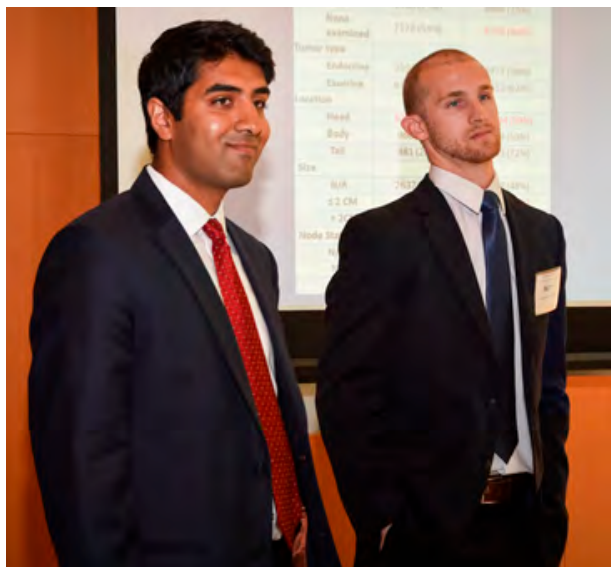

2016 Graduates of the Applied Outcomes Research Fellowship (AHEOR) Program at Fellows Day. Left to right: Ashok Vegesna, PharmD (Novartis AG) and Matthew Alcusky, PharmD, MS (Janssen, Inc).

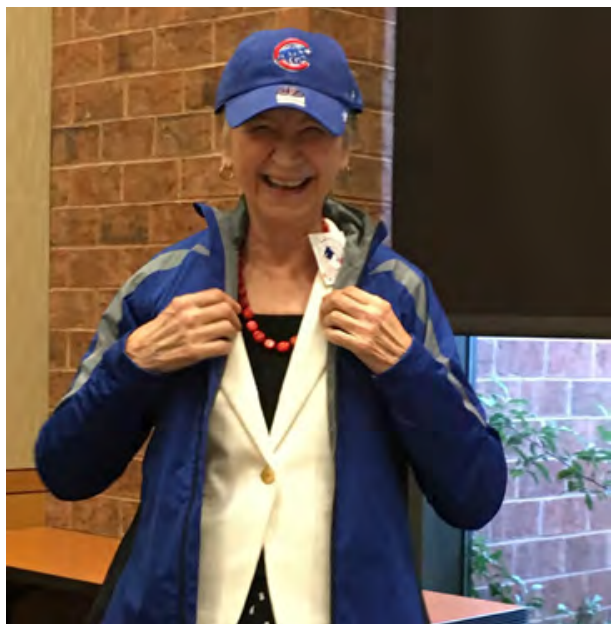

Dr. Golab was honored at the JCPH faculty dinner sporting her attire for her beloved Chicago Cubs team.

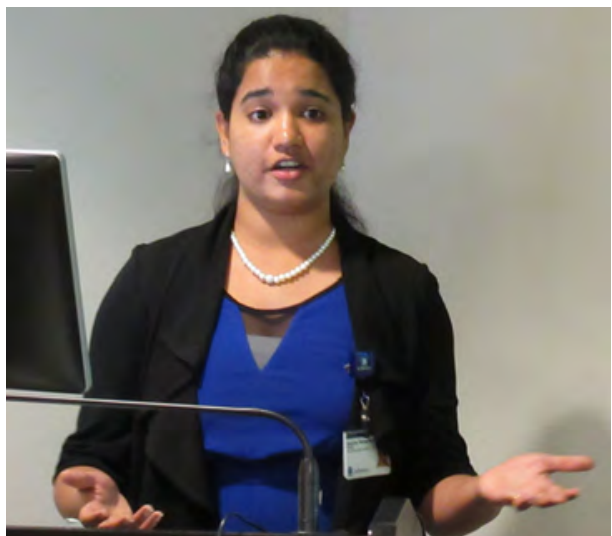

Deepika Ramachandran presents her MPH capstone presentation, "A Pilot Study to Assess the Association between Oral Health History and Oral Health Status among Diabetic Patients."

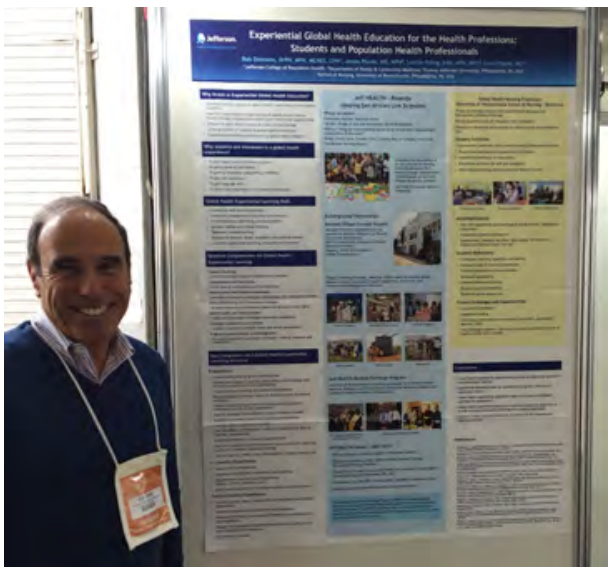

Dr. Simmons at the World Conference on Health Promotion and Health Education, International Union for Health Promotion and Health Education (IUHPE) in Curtiba, Brazil.

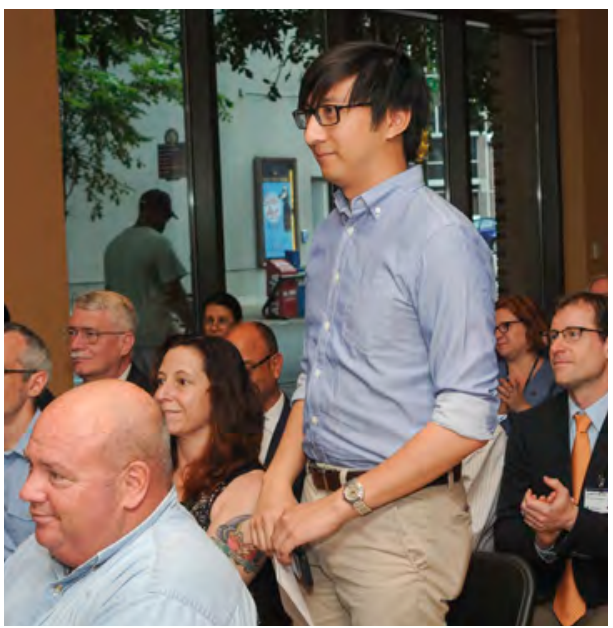

MPH student Randy Aviado at Class Night

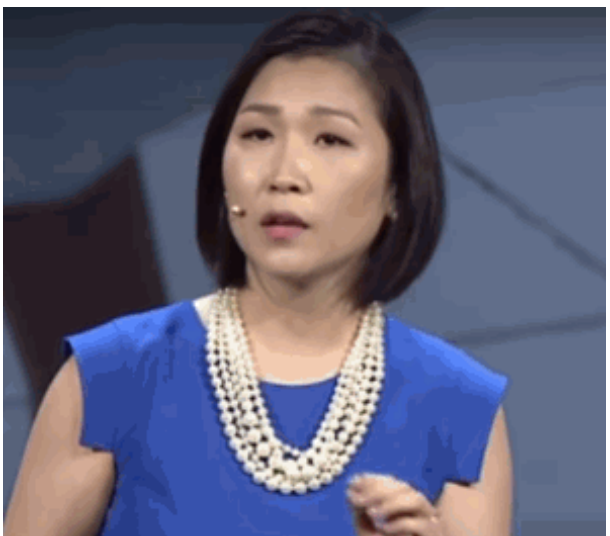

Dr. Seina Lee, JCPH Fellow (2006-2008) presented at the United State of Women Summit and shared her story on the importance of parental leave and work-life balance. Dr. Lee is Director, Health Economics and Outcomes Research at Janssen Immunology. Click here to view Dr. Lee's story. 


\section{Planetary Health: Report on the 7th Annual Global Health Conference}

With insightful logic and inspiring rhetoric, Lancet editor-in-chief Richard Horton, FRCP, FRCPCH, FMedSci, warned the Consortium of Universities for Global Health (CUGH) conference attendees that an exclusive focus on improving health will fail. He argued instead for 'planetary health.' "We have to cross outside of health and think about the relationship between health and other dimensions being defined as sustainability," Horton said in a keynote address at the annual CUGH conference in San Francisco April 9-11, 2016. The conference attracted more than 1,800 participants from around the world.

At a panel on progress against the HIV epidemic, Anthony Fauci, MD, Director, Institute of Allergy and Infectious Diseases

(NIAID) charted a cautiously optimistic course forward for confronting the HIV/AIDS epidemic. "I'm talking about turning around the trajectory. We are headed towards ending the pandemic as we know it." On the panel were some of the most influential voices in the epidemic: Fauci, Peter Piot, DTM, FRCP, FMedSci, London School of Hygiene and Tropical Medicine (and formerly with WHO); Eric Goosby, MD, UCSF School of Medicine (formerly USA Ambassador at Large and Global AIDS Coordinator); and Diane Havlir, UCSF School of Medicine.

The conference had a distinct interdisciplinary focus, with topics ranging from Zika to seasonal hunger (hunger before the crops are harvested), corruption, urban health, financing the sustainable development goals, violence, cancer prevention, refugees, soft diplomacy, non-communicable diseases (NCDs) and multiple topics in between. A panel on technology (which included Manu Prakash, genius inventor of the folding paper microscope) revealed lasers that can detect contaminants in food, hand-held X-ray machines, Bluetooth stethoscopes and a low-cost water treatment called Zimba. The conference was supplemented by a large selection of posters on each day. The following quotes illustrate the depth and innovation of the topics:

\section{"NCDs represent $53 \%$ of death and disability in LMICs and 1.6\% of global aid" \\ Chris Murray, MD, PhD, Director, Institute for Health Metrics and Evaluation, HME, University of Washington.}

\section{"Six percent of the human population lives in mega cities" The majority of population growth over the next 3 decades will occur in megacities. \\ David Vlahov, RN, PhD, FAAN, Dean, School of Nursing, UCSF}

"It is quite normal to treat pandemics and epidemics as health issues, but we know they also have deep societal impact and enormous economic consequences."

Maria Freire, PhD, President, Foundation for the National Institutes of Health (FNIH)

\section{"Corruption is a social determinant of health" \\ Jillian Kohler, PhD, University of Toronto, WHO Collaborating Center for Governance Accountability and Transparency in the Pharmaceutical Sector}

Preparing students for the real real-world and emerging themes in global health education were the topics of one of the preconference session. The next trends identified by panelists for public health educators to consider include: ${ }^{1}$

\section{- A focus on Africa (44\%), Middle East (21\%), Asia (12\%) \\ - 3 foci - agriculture and food security, conflict, climate \\ - Language - Arabic \\ - Work - the need for short-term expertise, while nationals provide long-term management}

Skill sets that employers expect students to learn in graduate school were discussed in-depth by both panels. Overwhelmingly the panelists emphasized the importance of soft skills (participatory competence, interprofessional, business savvy to run programs, language skills.) They also emphasized that in-depth expertise in a specific area or skill is the best way to assure employment. It was noted that $78 \%$ of employers need a balance of people with technical skills.

Mark your calendars! The $2017 \mathrm{CUGH}$ conference will be held in DC April 7-9. It will be co-hosted by Johns Hopkins and Makerere Universities.

Lucille B Pilling, EdD, MPH, RN

Adjunct Assistant Professor

Jefferson College of Population Health

Lucille.Pilling@jefferson.edu

\section{REFERENCES}

1. USAID Global Health Fellows II. Global health employer survey results. https://ghcompetencies.forumbee.com/t/h4xqd9/global-healthcompetencies. Accessed June 10, 2016.

\section{JCPH PUBLICATIONS}

Cooper M, Hong A, Beaudin E, Dias A, Kreiser $\mathrm{S}$. Ingersol CP, Jackson J. Implementing high reliability for patient safety. J Nursing Reg. 2016; 7(1):46-52. DOI: http://dx.doi. org/10.1016/S2155-8256(16)31041-9
Nash DB. Healthcare consumer as an innovator. MedPage Today. May 20, 2016.

Nash DB. Keeping score on public health. MedPage Today. June 23, 2016.
Nash DB. Navigating the "hassle map." Am Health \& Drug Benefits. 2016;9(4)186-187. 


\section{JCPH AT THE INTERNATIONAL SOCIETY FOR PHARMACOECONOMICS AND OUTCOMES RESEARCH (ISPOR) 21ST ANNUAL MEETING}

Chen BP, Cheng H, Romney M, Hsiaso

C. Literature review on hospital costs for patients undergoing hysterectomy.

Chen BP, Cheng H, Romney M, Hsiao C. Literature review on hospital costs for patients undergoing colectomy.

\section{Cunningham A, Chen PB, Delgado D.}

Factors influencing resection in locoregional pancreatic cancer patients.

McRae J, Calusi G, Liu M, Scongnamiglio V, Messina E, Polenzani L, Maio V. Erosion of empathy in primary care trainees.

McRae J, Prioli K, Schafer JJ, Cannon-Dang E, Harris LF, Pizzi LT. Developing beliefs that support vaccination: results from the pharmacists' pneumonia prevention program.
McRae J, Hegarty SE, Alcusky M, Vegesna A, Varga S, Keith SW, Del Canale S, Lombardi M, Maio V. Did a physician-targeted intervention that reduced potentially inappropriate prescribing to elderly patients also reduce related hospitalizations?

McRae J, Ezedike E, Varga S, Onukwugha E. Cost of illness studies from the patient's perspective: study design, characteristics and costs.

Varga S, Prioli K, Gitlin LN, Jutkowitz E, Pizzi LT. Developing consistent measure for cost analyses of dementia behavioral trials: a review of four study protocols.

Varga S, Lombardi M, Maio V. A review of current quality metrics for evaluating patientcentered medical homes.

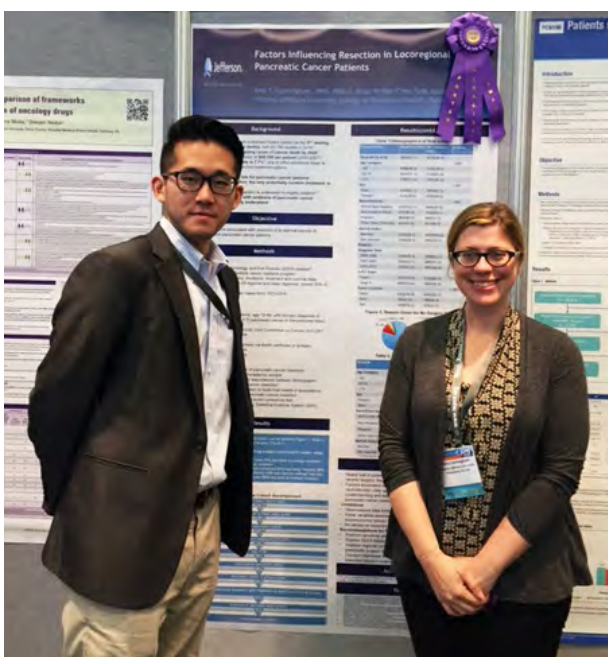

AHEOR Fellow Brian Po-Han Chen, ScM (Ethicon) and PhD Candidate Amy Cunningham, MPH received a best finalist award for their poster at ISPOR.

\section{JCPH PRESENTATIONS}

Ashton KC, Pilling LB. The sustainable development goals: implications and integration across the curricula. Presented at: Thomas Jefferson University Faculty Days, June 14, 2016, Philadelphia PA

Cooper M. Post graduate educational programs in QI. Presented at: ACMQ Medical Quality 2016, April 2, 2016, Washington, DC.

Golab C. A lifetime's reflections on teaching and learning: everything I know about best practices I learned from three daughters, two nuns, and one grandmother - with a little help from Maria Montessori and the fearless folks who brought us computers, the internet and the world wide web. Presented at Thomas Jefferson University Faculty Days, June 14, 2016, Philadelphia, PA.

Leon N, Hunter L, Plumb J, Simmons R, Pilling L. Engaging your students in global health education and practice experiences built into your curriculum. Presented at: Thomas Jefferson University Faculty Days, June 15, 2016, Philadelphia, PA.

Mclntire RK, Bowie AY. Prevalence and correlates of smoking in cars among residents of southeastern Pennsylvania.
Presented at: Pennsylvania Public Health Association Annual Conference, April 7, 2016, Lancaster, PA.

Mclntire, RK, Day K, Dyer S. Using a smartphone app to teach students practical epidemiologic skills. Poster presented at: Thomas Jefferson University Faculty Days, June 14, 2016 , Philadephia, PA.

McRae J, Chen BP, Liu M, Maio V, Callahan C, Louis DZ. Historic antibiotic use and hospitalization in a large cohort of children. Presented at: Academy of Managed Care Pharmacy (AMCP) and Specialty Pharmacy Annual Meeting, April 2016, San Francisco, CA

Plumb J, Brawer R, Simmons R, Romney M. Training healthcare professionals to serve as a catalyst to enhance health literacy. Presented at Thomas Jefferson University Faculty Days, June 14, 2016, Philadelphia, PA.

Simmons R. Training health educators to serve as catalysts to enhance health literacy: changing our healthcare system and educating consumers. Presented at: World Conference on Health Promotion and Health Education, International Union for Health Promotion and Health Education (IUHPE), May 23, 2016, Curtiba, Brazil.

Simmons R. Experiential global health education for the health professions: lessons learned from experienced based learning. Poster presented at: World Conference on Health Promotion and Health Education, IUHPE, May 24, 2016, Curtina, Brazil.

Simmons R. Efforts in strengthening the health promotion workforce to meeting contemporary challenges in Latin America: examples from Colombia. Presented at: World Conference on Health Promotion and Health Education, IUHPE, May 25, 2016, Curtina, Brazil.

Simmons R. Health literacy: a cross-cutting platform to improve health promotion efforts across countries - U.S. Experience. Presentation at: World Conference on Health Promotion and Health Education, IUHPE, May 25, 2016, Curtina, Brazil.

Williams L, Cooper M. The power of working together to prevent harm: a state-wide model for achieving high reliability. Presented at: Association of Nurse Executives (AONE) Annual Meeting 2016, April 1, 2016, Fort Worth, TX. 
REGISTER : AchDEMc PARTNER
TODAY!

Jefferson College of Population Health

\section{Population Health Colloquium Special Edition:}

Pop Health Policy \& Strategy

Under the New Administration

The Leading Forum on Innovations in Population Health \& Care Coordination December 1 - 2, 2016 • Washington, DC Hyatt Regency on Capitol Hill

CO CHAIRS:

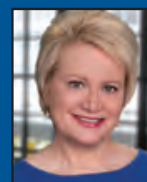

Susan Dentzer, President and -

-

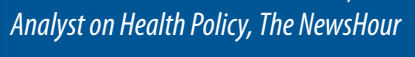

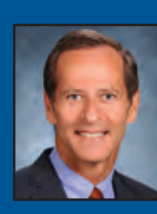

David B. Nash, MD, MBA, FACP, Dean, Jefferson College of Population Health, Thomas Jefferson University

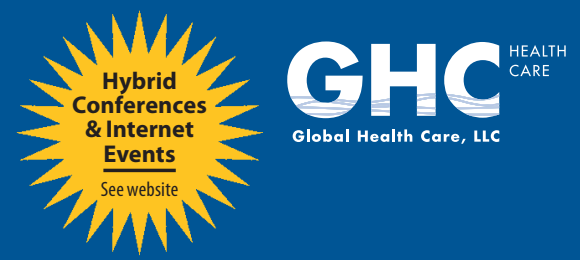

www.PopulationHealthColloquiumSpecialEdition.com

co-located with a Shared Plenary Session with The National MACRA MIPS/APM Summit The Leading Forum on MIPS, APMs and Other Emerging Value-based Payment Arrangements November 30 - December 2, 2016 • www.MACRASummit.com

... AND SAVE THE DATE:

THE SEVENTEENTH

Population
March $27-29,2017$

Philadelphia, PA

Please Visit our Website for Information on Speaking Proposals and Sponsorship Opportunities.

www.PopulationHealthColloquium.com 


\section{Population Health Matters}

Jefferson College of Population Health

Thomas Jefferson University

901 Walnut Street, 10th Floor

Philadelphia, PA 19107

\section{EDITORIAL BOARD}

\section{Editor}

David B. Nash, MD, MBA

Dean

Jefferson College of Population Health

\section{Managing Editor}

Emily J. Frelick, MS

Project Director

Jefferson College of Population Health

\section{Editorial Board}

Lauren Collins, MD

Associate Director, Jefferson Center for InterProfessional Education

Director, Jefferson Health Mentors Program Assistant Professor

Division of Geriatric Medicine

Department of Family and

Community Medicine

Sidney Kimmel Medical College

\section{Caroline Golab, PhD}

Associate Dean, Academic and

Student Affairs

Associate Professor

Jefferson College of Population Health

\section{Max Koppel, MD, MBA, MPH}

Clinical Associate Professor of Urology

Department of Urology

Thomas Jefferson University
Juan Leon, PhD

Director of Online Learning

Jefferson College of Population Health

Daniel Z. Louis, MS

Managing Director

Center for Research in Medical

Education and Healthcare

Sidney Kimmel Medical College

\section{Mary Lou Manning, PhD, CRNP,}

\section{CIC, FAAN}

Associate Professor

Jefferson College of Nursing

\section{Ronald E. Myers, PhD, DSW} Professor

Director of the Division of Population Science Department of Medical Oncology

Sidney Kimmel Medical College

\section{Colleen Payton, MPH, CHES}

Clinical Research Coordinator II

Department of Family and

Community Medicine

Thomas Jefferson University

\section{Etienne Phipps, PhD}

Director

Einstein Center for Urban Health

Policy and Research

Einstein Healthcare Network

Laura Pizzi, PharmD, MPH

Associate Professor

Jefferson College of Pharmacy

Joel Port, MHSA, CHE, CMPE

Chief Operating Officer

Accountable Care Organization of Pennsylvania

Jefferson Health System

\section{Randa Sifri, MD}

Associate Professor

Director, Research Development

Director, Faculty Development Research

Fellowship Department of Family

and Community Medicine

Thomas Jefferson University

\section{Rob Simmons, DrPH, MPH,}

\section{MCHES, CPH}

Associate Professor

Program Director, Public Health

Jefferson College of Population Health
Alexis Skoufalos, EdD

Associate Dean

Strategic Development

Assistant Professor

Jefferson College of Population Health

Rachel Sorokin, MD

Chief Patient Safety and Quality Officer Thomas Jefferson University Hospital

Elizabeth Speakman, EdD, RN, CDE, ANEF

Co-Director

Jefferson Center for

Interprofessional Education

Associate Professor

Jefferson College of Nursing

Steven Spencer, MD, MPH, FACP

Director of Population Health

Abington Health Physicians

Jefferson Health

Richard G. Stefanacci, DO, MGH, MBA, AGSF, CMD

Lecturer, Jefferson College of

Population Health

Chief Medical Officer, The Access Group
901 Walnut Street, 10th Flr. Philadelphia, PA 19107 